\title{
Synthesis of $\mathrm{Lu}_{2} \mathrm{O}_{3}-\mathrm{Bi}_{2} \mathrm{O}_{3} \mathrm{Nanoparticles}$
}

\author{
Alexandra Benediková ${ }^{1}$, Pavel Kejzlar ${ }^{1}$, Eva Kuželová Košt'áková ${ }^{1}$, David Tomka ${ }^{2}$, Jan Grégr ${ }^{1}$ \\ ${ }^{1}$ Technical university of Liberec. Studentská 1402/2, 46117 Liberec. Czech Republic. E-mail: alexandra.benedi- \\ kova@tul.cz,pavel.kejzlar@tul.cz, eva.kostakova@tul.cz,jan.gregr@tul.cz. \\ ${ }^{2}$ Institute of Plasma Physics of the CAS, Research Centre for Special Optics and Optoelectronic Systems \\ TOPTEC, Sobotecká 1660, 51101 Turnov, Czech Republic. E-mail: tomka@ipp.cas.cz.
}

This paper deals with a synthesis of a new ionising radiation attenuation composite material from $\mathrm{Lu}_{2} \mathrm{O}_{3}$ - $\mathrm{Bi}_{2} \mathrm{O}_{3}$ nanoparticles structure, that has never been described yet. The paper describes the preparation of $\mathrm{Lu}_{2} \mathrm{O}_{3}-\mathrm{Bi}_{2} \mathrm{O}_{3}$ nano- and microparticles by three methods: a self-combustion synthesis (types of fuel used were urea, citric acid, glycine, and tartaric acid), a solid-state method (processing by annealing under the melting point of $\mathrm{Bi}_{2} \mathrm{O}_{3}$ ) and a coprecipitation method (precipitation of ammonia of various concentrations). Polymer solution was prepared from $\mathrm{Lu}_{2} \mathrm{O}_{3}-\mathrm{Bi}_{2} \mathrm{O}_{3}$ nanoparticles, that were dissolved in ethanol and mixed with Polyvinyl Butyral. PVB $-\mathrm{Lu}_{2} \mathrm{O}_{3}-\mathrm{Bi}_{2} \mathrm{O}_{3}$ solution was homogenised by ultrasound. Afterwards, nanofibers were processed by an electrospinning method from $\mathrm{PVB}-\mathrm{Lu}_{2} \mathrm{O}_{3}-\mathrm{Bi}_{2} \mathrm{O}_{3}$ polymer solution. All the products were examined and characterised by Scanning electron microscopy and X-Ray diffraction. PVB - $\mathrm{Lu}_{2} \mathrm{O}_{3}-\mathrm{Bi}_{2} \mathrm{O}_{3}$ nanofibers were characterised and their X-Ray attenuation effect was tested. This paper proceeds from one of the author's bachelor thesis 1 .

Keywords: Metal oxides nanoparticles, nanofibers, X-Ray, lead-free materials, PVB.

\section{Introduction}

In recent years, there is a trend in searching new possibilities of applications of composite materials in the field of radiation protection. People use ionising radiation in many ways, for example in medicine, power engineering, security, etc. Ionising radiation attenuation materials which are used nowadays have many negative effects on user's health and better alternatives of this kind of protection should be explored. Following up on a previous research, the aim of the work is to develop a lead-free X-Ray protection material using $\mathrm{Lu}_{2} \mathrm{O}_{3}-\mathrm{Bi}_{2} \mathrm{O}_{3}$ nanoparticles at the instigation of SÚJCHBO (Czech National Institute for Nuclear, Chemical and Biological Protection). This material should be breathable, flexible, lightweight, non-toxic, effective and is meant to be a part of the new 'smart uniform', that will be used by Czech soldiers in dangerous environments. It is possible that this material could serve in many different fields of human activities. Synthesis of $\mathrm{Lu}_{2} \mathrm{O}_{3}-\mathrm{Bi}_{2} \mathrm{O}_{3}$ nanoparticles has never been described yet, so, for the research, synthesis methods of similar compounds (Fe$\mathrm{BiO}_{3}$, ferrites, perovskites) were found [2, 3]. After thorough research, three methods were chosen for the preparation of $\mathrm{Lu}_{2} \mathrm{O}_{3}-\mathrm{Bi}_{2} \mathrm{O}_{3}$ nano- and microparticles.

\section{Solid-state top-down method:}

This method uses an easy top-down principle. Preparation of oxidic microparticles and their subsequent mechanical modification was used [4]. In the mentioned paper, a preparation of $\left(\mathrm{Bi}_{2} \mathrm{O}_{3}\right)_{1-\mathrm{x}}\left(\mathrm{Lu}_{2} \mathrm{O}_{3}\right)_{\mathrm{x}}(\mathrm{x}=$ $0.1,0.2,0.3,0.4,0.5)$ compounds is described. $\left(\mathrm{Bi}_{2} \mathrm{O}_{3}\right)_{1-\mathrm{x}}\left(\mathrm{Lu}_{2} \mathrm{O}_{3}\right)_{\mathrm{x}}$ microparticles were produced as a non-toxic yellow pigment and characterised by TGA and DTA analysis (Graph 1). DTA analysis showed, that $735{ }^{\circ} \mathrm{C}$ is the minimal temperature of an endothermic effect and $\mathrm{Lu}_{2} \mathrm{O}_{3}$ dissolves in $\mathrm{Bi}_{2} \mathrm{O}_{3}$ structure. $735{ }^{\circ} \mathrm{C}$ is the temperature at which $\mathrm{Bi}_{2} \mathrm{O}_{3}$ crystallises in delta modification ${ }^{5}$. Delta- $\mathrm{Bi}_{2} \mathrm{O}_{3}$ has the lowest density of all its modifications, so there is probably the greatest chance, that $\mathrm{Lu}^{3+}$ ions would enter the crystal structure of $\mathrm{Bi}_{2} \mathrm{O}_{3}$. This process is the basis of the solid-state method of oxidic nanoparticles synthesis.

\section{Self-combustion synthesis:}

Self-combustion synthesis, a.k.a. self-propagating high temperature synthesis is a fast and easy way to prepare oxidic nanoparticles. The right choice of homogenous oxidation reagent and organic fuel is crucial for this method. Glycine, citric acid, tartaric acid and urea are some examples of organic fuels that can be used. Each of those has its own properties that can influence the course of the self-combustion reaction (speed, activation energy, etc.) [6].

\section{Coprecipitation:}

Coprecipitation is an easy and reproducible method intended for preparation of metal nanoparticles and metal oxides nanoparticles. This method consists of few basic steps: chemical reaction, nucleation, 
growing and agglomeration. Supersaturated solution is essential to start the precipitation mechanism [7].

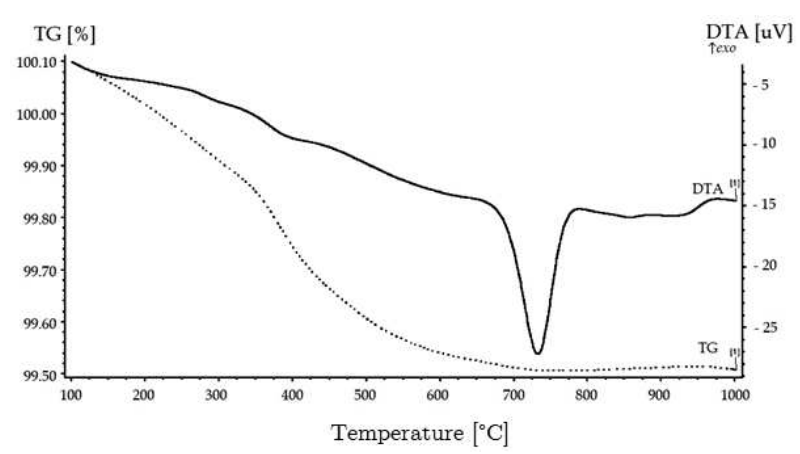

Graph 1 TG $A$ and DTA analysis of (Bi2O3)1$x(\mathrm{Lu} 2 \mathrm{O} 3) x(x=0.1,0.2,0.3,0.4,0.5)[3]$

\section{Experimental}

\section{Solid-state top-down method:}

For this method, $\mathrm{Lu}_{2} \mathrm{O}_{3}$ and $\mathrm{Bi}_{2} \mathrm{O}_{3}$ oxides were mixed in stoichiometric amount and then were homogenized in an agate mortar. Afterwards, the homogenized mixture was gradually calcinated in an electric furnace up to the maximum temperature $770{ }^{\circ} \mathrm{C}$ within 2 hours. The product was homogenized in agate mortar and placed into the electric furnace up to the maximum temperature $770{ }^{\circ} \mathrm{C}$ within 2 hours again. The final product was homogenized again and had a form of fine yellow powder (Fig. 1).

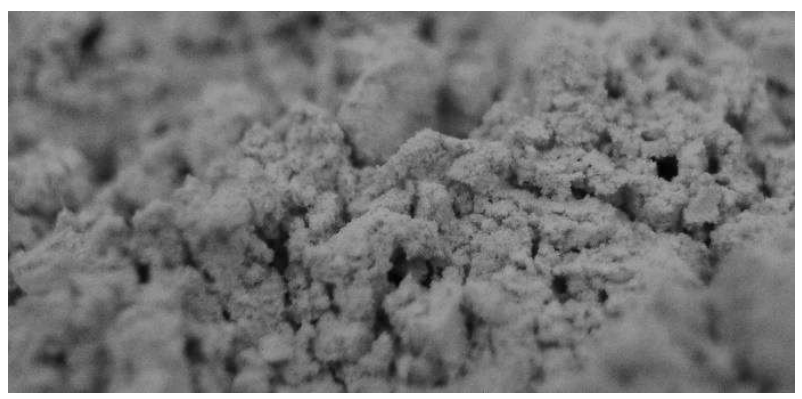

Fig. 1 Final product of solid-state method

\section{Self-combustion synthesis:}

Self-combustion synthesis methodology proceeds from previous research [8]. This methodology was not exactly suitable for these metal oxides reactions, so it had to be modified - the temperature of the final heating process was increased to $800{ }^{\circ} \mathrm{C}$. For the selfcombustion synthesis experiments, metal oxides were transferred to precursors in form of nitrates, $\mathrm{Bi}\left(\mathrm{NO}_{3}\right)_{3}$ and $\mathrm{Lu}\left(\mathrm{NO}_{3}\right)_{3}$ by mixing starting oxides with nitric acid and heating the mixture up. For this kind of reactions, different fuels were chosen - glycine, citric acid, urea and tartaric acid. Nitrate precursors were mixed with fuel in stoichiometric amounts and then heated up to obtain gel consistent solution. Final solution reacted by self-combustion mechanism that was initiated in several ways - by heating it in a microwave oven, heating it on an electric plate and heating it by a focused sun beam. In this phase, two kinds of product appeared - black and yellow powder. To homogenise the final product, the mixture was processed in agate mortar and heated up to $800{ }^{\circ} \mathrm{C}$ in an electric furnace. Again, the product in form of fine yellow powder appeared. It was observed at this point, that there are little differences in colour and structure depending on the fuel that was used.

\section{Coprecipitation:}

For this method, it was necessary to prepare nitrate precursors first. Nitrate mixture solution was added by drops from burette to a beaker placed on a magnetic agitator containing aqueous solution of ammonium hydroxide $\mathrm{NH}_{4} \mathrm{OH}$. This process led to a white precipitate, that needed to be dried, then it was placed into an electric furnace and heated up to $800{ }^{\circ} \mathrm{C}$. The final product was a fine yellow powder.

\section{PVB - $\mathrm{Lu}_{2} \mathrm{O}_{3}-\mathrm{Bi}_{2} \mathrm{O}_{3}$ nanofibers preparation:}

Micro- and nanoparticles prepared in previous steps were dissolved in ethanol. To homogenise the particles, the solution was processed by ultrasound (20 $\mathrm{kHz} / 10 \mathrm{~min}$.). Homogenised solution was then mixed with a certain amount of PVB (depending on required concentration ratio of $\mathrm{PVB}$ to nanoparticles), which produced a polymer solution ready for DC electrospinning. Concentration of particles to PVB was 3:1 and 8:1. Polymer solution has been processed by the string DC electrospinning method on the $\mathrm{Na}$ nospider machine under following conditions: electrode distance: $16 \mathrm{~cm}$, supply voltage: $30 \mathrm{kV}$ and temperature: $22.8^{\circ} \mathrm{C}$.

\section{Results and discussion}

All of the synthesised products were analysed by SEM, EDX (Scanning electron microscope Zeiss Ultra Plus with full microanalytic set EDS + WDS + EBSD), Technical university of Liberec) and XRD (XRay diffractometer X'Pert PRO, VŠCHT Prague). Solid-state method is very simple and effective, so it would be desirable for this method to provide a pure and homogenous product. SEM and XRD analysis (VŠCHT Prague) showed, that the solid-state method leads to a polydistributed and non-homogenous product. Due to XRD analysis, stoichiometric structure of this product is $\mathrm{Lu}_{0.67} \mathrm{Bi}_{1.33} \mathrm{O}_{3}$, so we know that part of $\mathrm{Lu}_{2} \mathrm{O}_{3}$ oxide stays out of reaction. It is probably impossible to get $\mathrm{Lu}_{2} \mathrm{O}_{3}-\mathrm{Bi}_{2} \mathrm{O}_{3}$ compound with any other stoichiometry by this method.

As it is possible to see on Fig. 2, nanoparticles prepared by the solid-state method form microparticles. These bigger units are very hard to shatter, so this product cannot be homogenised.

Most of the fuels used for self-combustion synthesis react too quickly. The most effective fuel 
for the self-combustion synthesis of $\mathrm{Lu}_{2} \mathrm{O}_{3}-\mathrm{Bi}_{2} \mathrm{O}_{3}$ nanoparticles is tartaric acid. Nanoparticles prepared with tartaric acid are homogenous (see Fig. 3) and according to an XRD analysis, these nanoparticles are very pure. Product crystallises in cubic system with lattice parameter $\mathrm{A}=5.41 \AA$. Most of the particles have a size of $50-200 \mathrm{~nm}$. Nanoparticles prepared by this method form bigger units, but it is obvious that it would be easy to shatter them, for example with ultrasound.

Coprecipitation reaction provided the most unified product - spherical nanoparticles in range of $50-100 \mathrm{~nm}$ (Fig. 4). XRD analysis was not able to specify lattice structure of this product, the closest crystal structure is cubic compound $\mathrm{Ce}_{0.6} \mathrm{Lu}_{0.4} \mathrm{O}_{1.8}$ with the same lattice parameter $A \approx 5.4 \AA$. To obtain as homogenous product as possible, coprecipitation aperture was enhanced with ultrasound, so that the particles could be shattered shortly after their formation. Quantitative analysis showed, that as the only one of the three methods, coprecipitation provided demanded product with stoichiometric amount of $\mathrm{Lu}_{2} \mathrm{O}_{3}: \mathrm{Bi}_{2} \mathrm{O}_{3}$ in a ratio of 1:1.

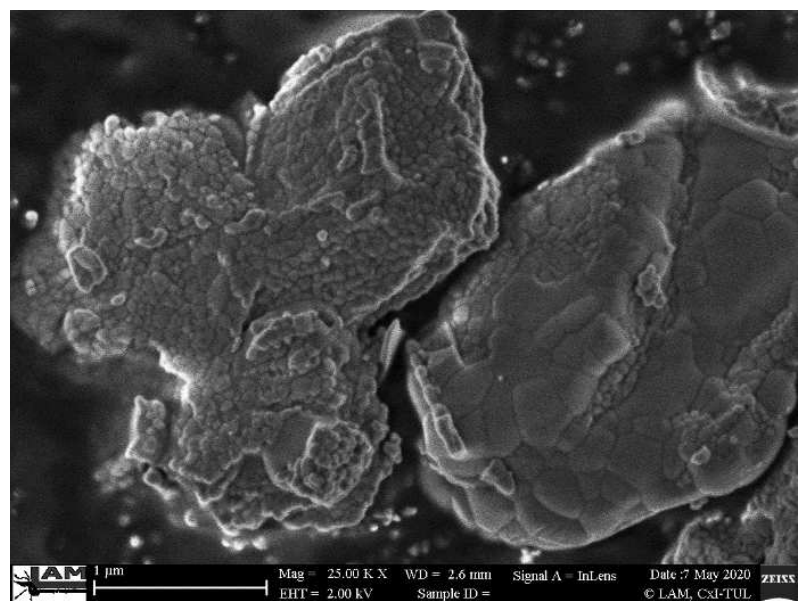

Fig. 2 SEM of solid-state $\mathrm{Lu}_{2} \mathrm{O}_{3}-\mathrm{Bi}_{2} \mathrm{O}_{3}$ nanoparticles at $25 k x$

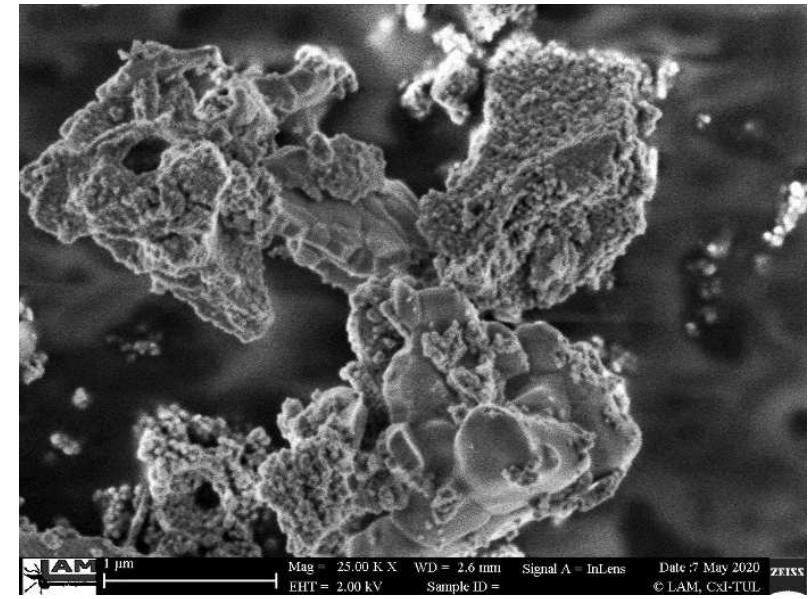

Fig. 3 SEM of self-combustion synthesis $\mathrm{Lu}_{2} \mathrm{O}_{3}-\mathrm{Bi}_{2} \mathrm{O}_{3}$ nanoparticles at $25 \mathrm{kx}$

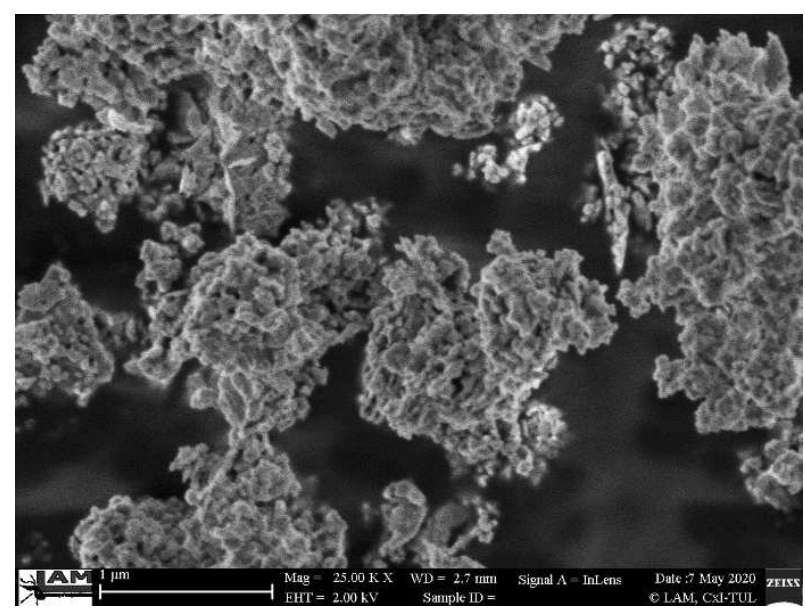

Fig. 4 SEM of coprecipitation $\mathrm{Lu}_{2} \mathrm{O}_{3}-\mathrm{Bi}_{2} \mathrm{O}_{3}$ nanoparticles at $25 \mathrm{kx}$

All the products were processed to make up nanofibrillar textile. Results show that this textile is nontoxic, breathable and very flexible. Depending on the concentration of particles it has its specific colour (Fig. $5)$.

Fig. 5 Processed nanofibre textile with concentration of particles to PVB 8:1 

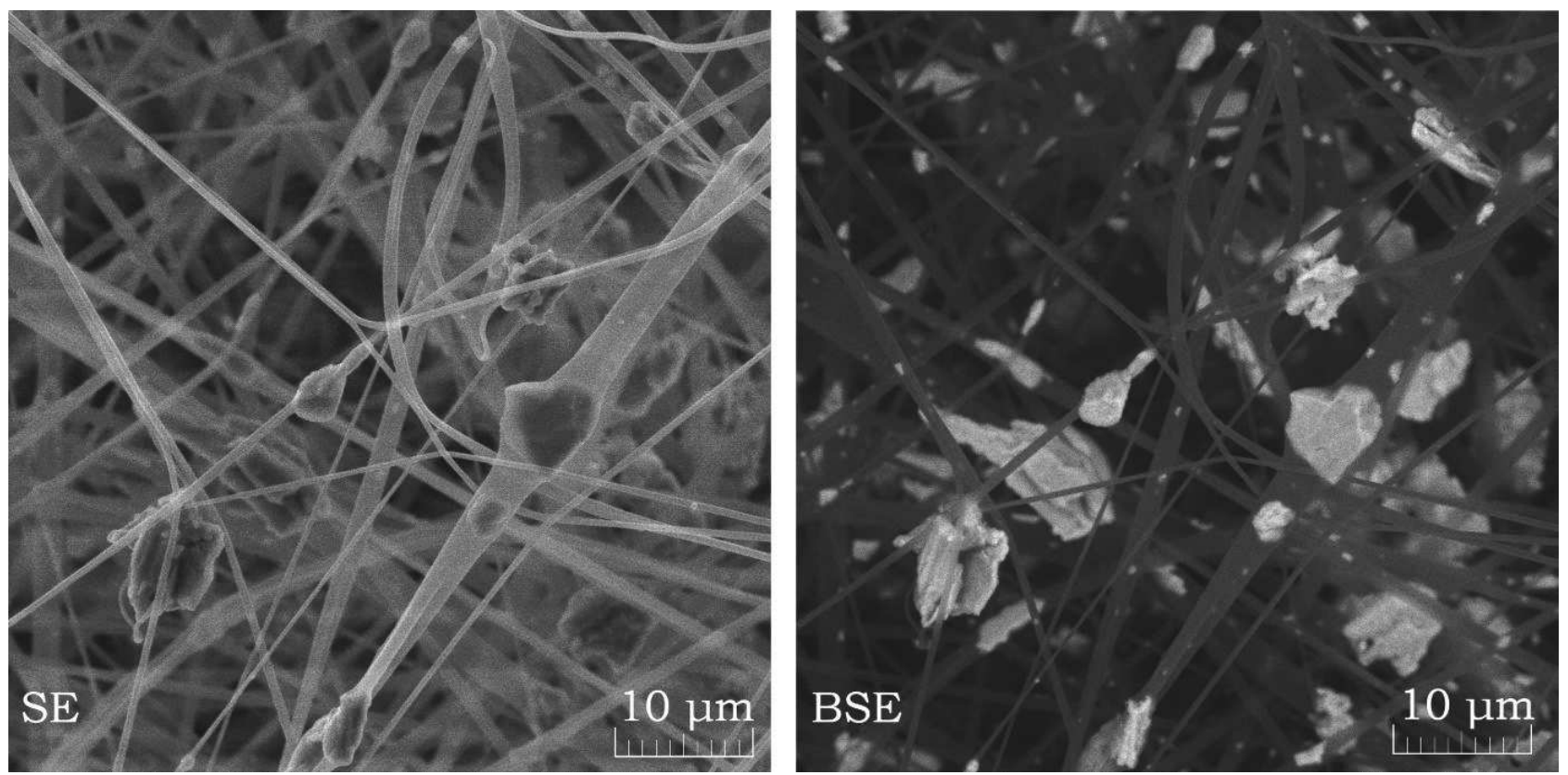

Fig. 6 SEM images of prepared $\mathrm{Lu}_{2} \mathrm{O}_{3}-\mathrm{Bi}_{2} \mathrm{O}_{3}$ textile (self-combustion synthesis method nanoparticles), 5 kx

Figure 6 shows the way of implementation of oxidic nano- and microparticles prepared by the solidstate method. The image was taken by scanning electron microscopy. The left image is provided by secondary electrons and the right image is provided by back scattered electrons. SEM images of the structure were taken in topographical contrast using secondary electron detector.[8]

The prepared textile is very lightweight and could be comfortable to wear. The most important property of this textile is the radiation attenuation effect. This was tested on one of the potential workplaces - X-Ray examination in a hospital (Fig. 7).

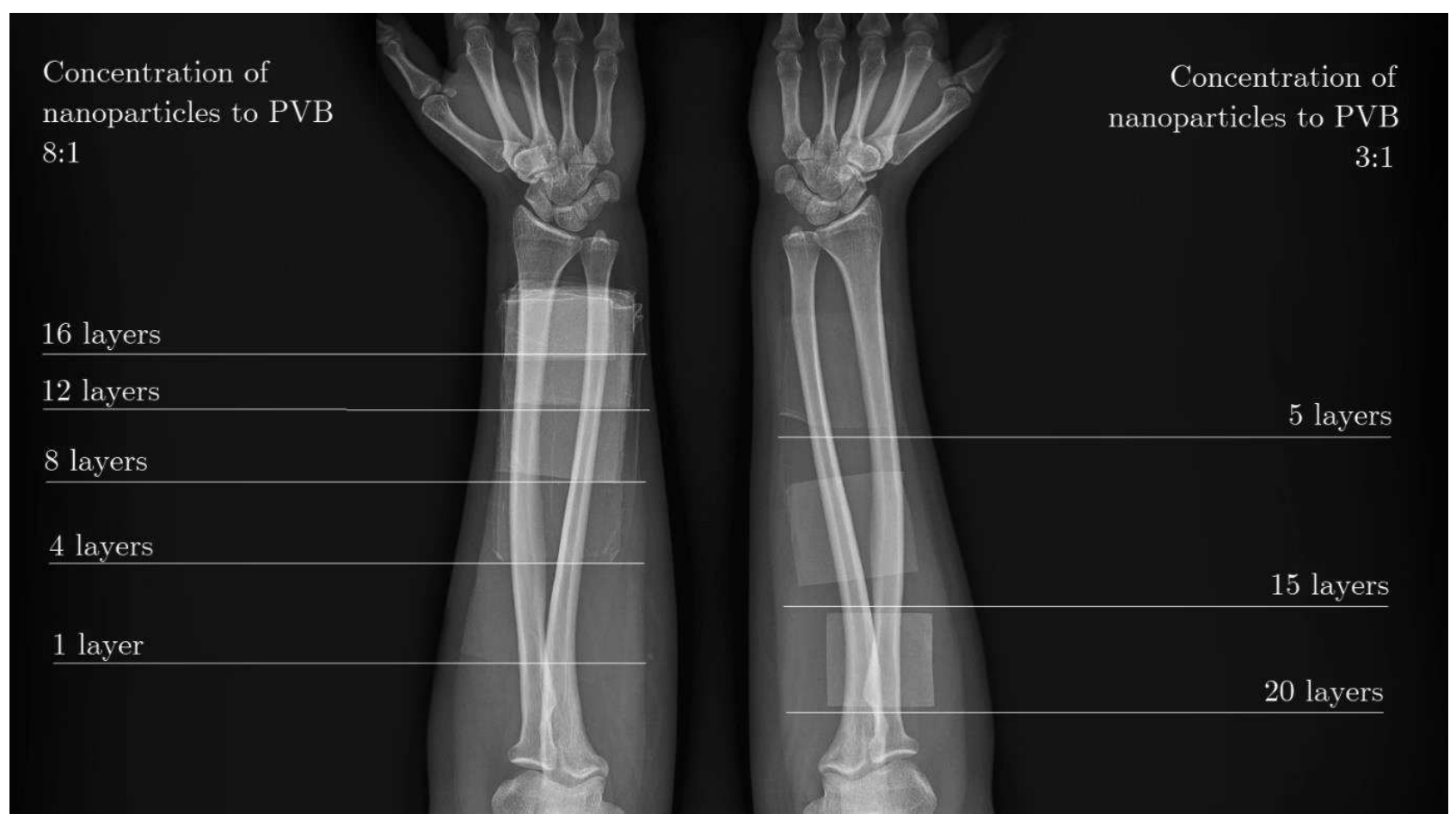

Fig. 7X-Ray image of radiation attenuation effect of prepared $\mathrm{Lu}_{2} \mathrm{O}_{3}-\mathrm{Bi}_{2} \mathrm{O}_{3}$ textile

On Fig. 7, a radiation attenuation effect of $\mathrm{Lu}_{2} \mathrm{O}_{3}-$ $\mathrm{Bi}_{2} \mathrm{O}_{3}$ is shown. Two polymer solutions of different concentrations of the coprecipitation particles were prepared. After processing these solutions by the electrospinning method, two types of nanofibrillar textile were made. The textile was cut into pieces and put together in various numbers of layers to see how the attenuation effect would intensify. To find out 
which concentration ratio of particles to PVB could be adequate for maximum attenuation effect, nanofibrillar textile of concentration 19:1 ratio of $\mathrm{Bi}_{2} \mathrm{O}_{3}$ nanoparticles to PVB was prepared. As seen on Fig. 8, five layers of this textile are able to attenuate around $75 \%$ of radiation.

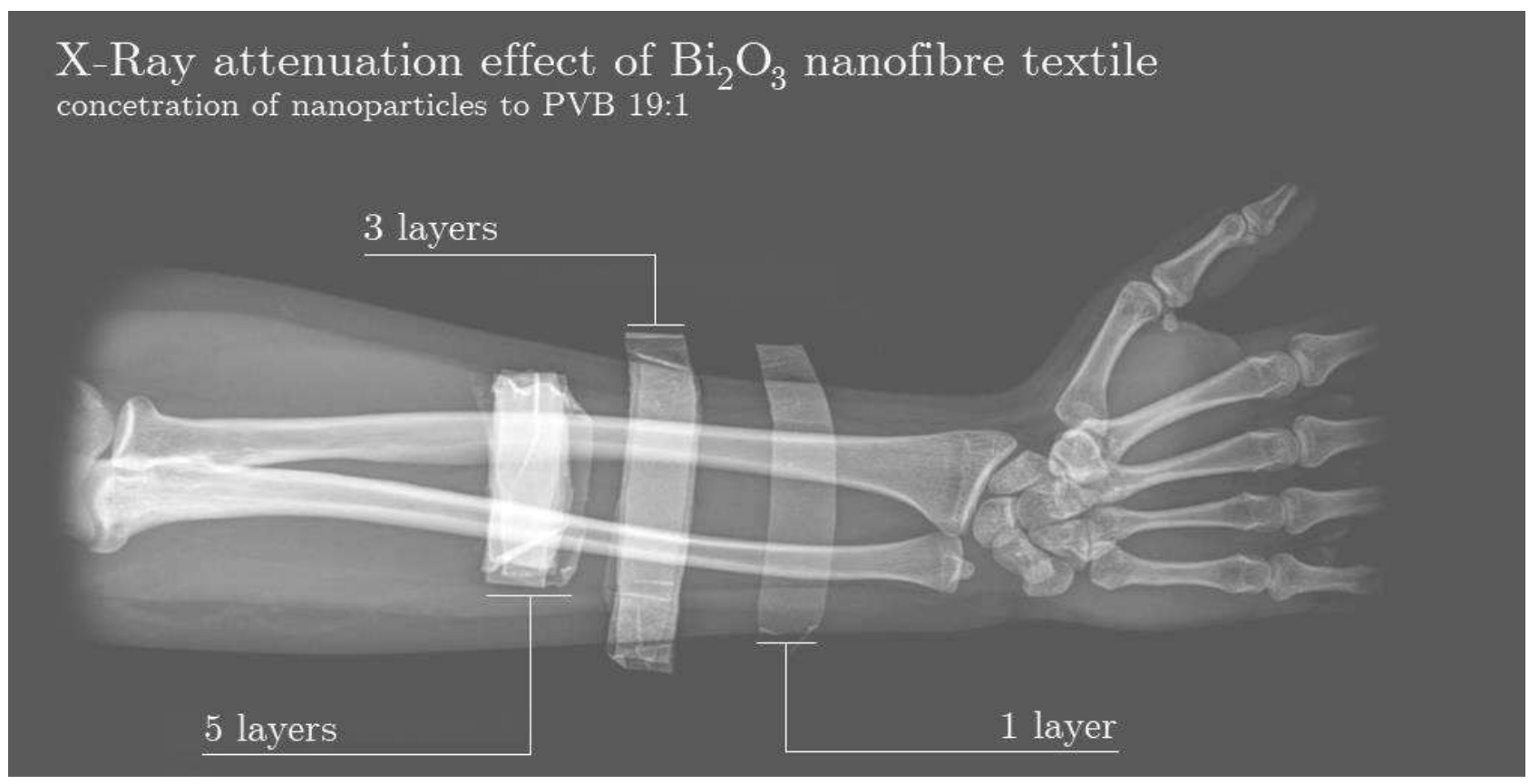

Fig. 8 X-Ray image of radiation attenuation effect of prepared $\mathrm{Bi}_{2} \mathrm{O}_{3}$ textile

\section{Conclusion}

All the examined methods of producing $\mathrm{Lu}_{2} \mathrm{O}_{3}$ $\mathrm{Bi}_{2} \mathrm{O}_{3}$ nanoparticles are suitable for a synthesis of oxidic nanoparticles. Solid state method provides heterogenous particles of the size in range $100 \mathrm{~nm}-3 \mu \mathrm{m}$ and this method seems to be the most effective. On the other hand, solid-state method leads to a polydistributed and non-homogenous product with stoichiometry $\mathrm{Lu}_{0.67} \mathrm{Bi}_{1.33} \mathrm{O}_{3}$, so we know that part of $\mathrm{Lu}_{2} \mathrm{O}_{3}$ oxide stays out of reaction. The most effective fuel for the self-combustion synthesis of $\mathrm{Lu}_{2} \mathrm{O}_{3}-\mathrm{Bi}_{2} \mathrm{O}_{3}$ nanoparticles is tartaric acid. This method leads to nanoparticles with stoichiometric amount of $\mathrm{Lu}_{2} \mathrm{O}_{3}: \mathrm{Bi}_{2} \mathrm{O}_{3}$ in a ratio of 1:1. Nanoparticles prepared with tartaric acid are homogenous and easy to shatter by ultrasound. Coprecipitation reaction provided the most homogenous product - spherical nanoparticles in range of $50-100 \mathrm{~nm}$ with stoichiometric amount of $\mathrm{Lu}_{2} \mathrm{O}_{3}: \mathrm{Bi}_{2} \mathrm{O}_{3}$ in a ratio of $1: 1$. The particles of size 50 $-200 \mathrm{~nm}$ in PVB solution are very suitable for electrospinning processing. When incorporated into the nanofibers, these nanoparticles are able to effectively attenuate X-Ray.

\section{Acknowledgement}

The result was obtained through the financial support of the grant 'Intelligent textiles for protection against CBRN substances' of Ministry of Interior of the Czech Republic; VI20172020059.

\section{References}

[1] BENEDIKOVÁ, A. (2020). $\mathrm{LuBiO}_{3}$ nanoparticles for ionizing radiation attenuation. Bachelor thesis, Technical university of Liberec, 2020.

[2] ORTIZ-QUIÑONEZ, J. L., DÍAZ, D., ZUMETA-DUBÉ, I., ARRIOLASANTAMARÍA, H., BETANCOURT, I., SANTIAGO-JACINTO, P., NAVAETZANA, N. (2013). Easy Synthesis of HighPurity $\mathrm{BiFeO}_{3}$ Nanoparticles: New Insights Derived from the Structural, Optical, and Magnetic Characterization. Inorganic Chemistry. 16 September 2013. Vol. 52, no. 18, p. $10306-$ 10317. DOI $10.1021 /$ ic 400627 c.

[3] HASAN, M., ISLAM, F. et al. (2016). A soft chemical route to the synthesis of $\mathrm{BiFeO}_{3}$ nanoparticles with enhanced magnetization. Materials Research Bulletin. 2016, 73, 179-186. ISSN 00255408. DOI: 10.1016/j.materresbull.

[4] ŠULCOVÁ, P.; PROKLEŠKOVÁ E., BYSTRZYCKI, P., TROJAN, M. Thermal analysis of the $\left(\mathrm{Bi}_{2} \mathrm{O}_{3}\right)_{1-\mathrm{x}}\left(\mathrm{Lu}_{2} \mathrm{O}_{3}\right)_{\mathrm{x}}$ compounds. Journal of Thermal Analysis and Calorimetry. DOI: 10.1007/s10973-009-0128-y.

[5] GIRAUD, S. (1999). Nowvelles phases du système $\mathrm{PbO}-\mathrm{Bi}_{2} \mathrm{O}_{3}-\mathrm{M}_{2} \mathrm{O}_{5} \quad(\mathrm{M}=\mathrm{P})$ : synthèses, structures, caractérisations et phases homologues $(M=V, A s)$. 
Cristallographie, 1999. Université des sciences et technologies de Lille.

[6] KOPP ALVES, A., BERGMANN C. P., BERUTTI F. A. (2013). Novel Synthesis and Characterization of Nanostructured Materials. Berlin, Heidelberg: Springer Berlin Heidelberg, s. 1122. ISBN 978-3-642-41274-5.

[7] DIRKSEN, J. A., T.A. Ring. (1991). Fundamentals of crystallization: kinetic effects on particle size distributions and morphology. Chemical Engineering Science. 1991, pp. 2389-2427.
[8] SEIBERT, O., GRÉGR, J., KEJZLAR, P. (2019). The Preparation of Iron Oxide Nanoparticles by a Self-combustion Method. Manufacturing Technology. 2019. Vol. 19, no. 4, p. 5.

[9] KEJZLAR, P., ŠVEC, M., MACAJOVÁ, (2014). The usage of backscattered electrons in scanning electron microscopy. Manufacturing Technology. October 2014, Vol. 14, No. 3, p. 333 $-336$. 